\title{
DOSSIER
}

\section{TRABAJO Y EMPLEO PÚBLICO \\ EN LA CIUDAD DE MÉXICO, \\ SIGLOS XIX Y XX \\ PRESENTACIÓN}


a partir del siglo xix. La actividad productiva y comercial, así como la administración pública generaron nuevas posiciones de trabajo en una estructura que se fue haciendo más compleja con el paso del tiempo y con la aparición de reglas precisas en los nuevos tipos de establecimientos productivos y comerciales. La ciudad fue el espacio privilegiado para este proceso de ampliación y especialización de los perfiles de trabajo en medio de la industrialización, la ampliación del consumo y la acumulación de capital.

Esa expresión poco usada en los últimos tiempos de “mundo del trabajo” se podría volver a tomar como referencia para pensar en la diversidad de labores, en las distintas formas de organización del trabajo, en las escalas y gradaciones establecidas en los nuevos espacios laborales, así como en la configuración de perfiles ocupacionales establecidos de acuerdo con el conocimiento, el género y la condición social. De manera paralela a la configuración de los estados nacionales en el siglo XIX, se fueron consolidando modelos administrativos y técnicos en buena 
parte del mundo occidental. Tomar como tema de estudio la organización administrativa o a quienes trabajan en ella remite a pensar en la forma como se constituyeron las burocracias y en el papel de las normas y legislaciones que la sustentaban, así como en la racionalización de la organización del trabajo y en la disciplina requerida para asumir los retos de la oficina. Muchos de estos aspectos de la organización administrativa de carácter novedoso en el siglo xIX se fueron convirtiendo en normales en las estructuras, normas y jerarquías laborales de instancias de la administración pública y de las empresas privadas.

La historia del trabajo tiene la tarea pendiente de explorar y analizar con mayor profundidad esta ampliación de las ocupaciones y las tareas administrativas que se derivan del proceso de especialización, de la división funcional, de las jerarquías administrativas y de la minuciosa labor de registro y seguimiento de las actividades que se realizaban. ${ }^{1} \mathrm{La}$ investigación histórica requiere abordar los trabajos en sí mismos, sus características específicas, los conocimientos requeridos para llevarlos a cabo y las relaciones establecidas entre quienes laboraban en estos espacios. También se necesita conocer esta organización burocrática y cómo se fue extendiendo, incluso a las oficinas públicas en las nuevas repúblicas en Latinoamérica. Pensar en estos tipos de trabajo y hacer referencia a los rasgos de la burocracia nos permitirán establecer un marco de análisis común a los trabajos que forman parte de este dossier sobre la historia social de algunos empleos públicos en la capital mexicana durante las primeras décadas del siglo xx, un periodo en el que hay, sin duda, un fortalecimiento del aparato administrativo que aparece de manera paralela a la consolidación del Estado posrevolucionario.

${ }^{1}$ Lutz Raphael enuncia éstas como las tres características centrales de la burocracia. Lutz Raphael, Ley y orden. Dominación mediante la administración en el siglo XIX, Madrid, Siglo Veintiuno Editores, 2008. 
El propósito de estos artículos es explorar el empleo en diversos ámbitos de la administración pública de la capital mexicana y abrir caminos para caracterizar y analizar el mundo de los empleados y empleadas. Con este fin en estas páginas iniciales nos proponemos señalar algunos ejes de análisis para abordar la historia de estos empleados y estas empleadas como tema de estudio. Más que pensar en los procesos de consolidación del aparato administrativo, nos interesa reflexionar sobre el carácter del empleo público, la forma como se perfilaron los diversos puestos en instancias con diversidad de objetivos, la asociación de este trabajo con sectores sociales determinados y la creciente participación de las mujeres en puestos y campos del sector público. Estas líneas de análisis pueden ser guías para entender las potencialidades que tiene el estudio de estos empleados y para entender cómo se va consolidando este mundo del trabajo durante los dos últimos siglos.

Reconocidos investigadores han referido los temas y problemas relacionados con la historia del trabajo. Por ejemplo, Mirta Lobato señala que interesan, por un lado, los estudios relacionados con la transformación de las condiciones del trabajo y, por el otro, el análisis de las organizaciones e ideologías. En relación con el primer punto, Lobato afirma que hay varios ámbitos a tomar en cuenta: labores realizadas, horarios y condiciones en los distintos lugares. ${ }^{2}$ Justamente, la exploración de estos rasgos permite entender las particularidades de la especialización y los requerimientos de la racionalización del trabajo tanto en la fábrica como en los nuevos espacios laborales y, en particular, en las oficinas. Como hemos señalado, el crecimiento económico, el fortalecimiento estatal y los cambios en las condiciones

\footnotetext{
2 Mirta Zaida Lobato, “Historia del trabajo: género y clase”, en Jorge CerNADAS y Daniel Lvovich (eds.), Historia, ¿para qué? Revisitas a una vieja pregunta, Buenos Aires, Universidad Nacional General Sarmiento y Prometeo Libros, 2010, p. 224.
} 
materiales generaron cambios en esas condiciones de trabajo para hombres y mujeres.

Lutz Raphael señala algunas peculiaridades de los estilos de administración en los estados modernos que pueden servir de referencia para observar la organización de la administración de la burocracia. Entre ellos, refiere la introducción de procesos de incorporación por mérito, la formalización de procedimientos, el establecimiento de registros escritos, la centralización de decisiones, así como la inspección y el establecimiento de jerarquías militares en la estructura de las oficinas. ${ }^{3}$ Estos rasgos están relacionados, en primer lugar, con cualidades de estos hombres y mujeres y con las posibilidades de formación en las escuelas creadas con el fin de capacitar en habilidades necesarias para estos trabajos. El mérito estaba relacionado con la capacitación y la profesionalización creciente de algunos oficios y con los conocimientos específicos para realizar labores o manejar equipos. Tanto en las antiguas profesiones como en las nuevas se hizo necesaria una mayor cualificación y en el proceso de delimitación funcional de forma paralela hubo una asociación de oficios y labores con géneros, edades e, incluso, orígenes sociales y hasta étnicos.

A veces no bastaba con la capacitación o con cumplir con las condiciones de edad o género. También había un perfil social relacionado con formas de ser o comportarse, con orígenes sociales y con relaciones establecidas. La incorporación por mérito era una característica de esta nueva configuración. Sin embargo, la oferta de empleo público generó más bien posibilidades para fortalecer relaciones clientelares. En estas estructuras militares en donde prevalecía un sistema de decisiones centralizadas, las lealtades personales se hicieron más fuertes y tenían que ver con la pertenencia o no a organizaciones o con vínculos

3 Lutz Raphael, Ley y orden. Dominación mediante la administración en el siglo XIX, Madrid, Siglo Veintiuno Editores, 2008, pp. 28-30. 
políticos o solidaridades personales o familiares. Estas características del empleo público pueden ser exploradas en los fondos y secciones de los archivos que dan cuenta de la actividad de las distintas instancias de la burocracia. Allí se encuentran indicios de esas formas de contratación, así como de las calidades de algunos de los funcionarios. El registro sistemático de actividades de la burocracia permite explorar la historia que aquí estamos proponiendo, una historia que indaga las condiciones sociales y laborales de empleados públicos a comienzos del siglo xx.

Estas condiciones de trabajo han comenzado a ser examinadas en la investigación histórica tomando como punto de referencia y de análisis ámbitos como el género o la identidad social. En el caso del género, investigaciones relevantes han estudiado las condiciones de trabajo de las mujeres, sus posibilidades laborales, la profesionalización o las relaciones de género establecidas a la par de las nuevas condiciones de organización laboral. En contextos diferentes, tanto en Europa como en América Latina, los investigadores han avanzado en pensar este binomio trabajo-género a la luz de los procesos de modernización, de las posibilidades laborales y de las explicaciones de los contemporáneos sobre las diferencias sociales. La historiadora Ulla Wikander, en su estudio sobre mujer y trabajo en el caso de Europa, señala: "La búsqueda de un trabajo ha significado para las mujeres de los últimos 200 años moverse por una selva de reglas restrictivas y molestas, que se entrelazaban de manera más sutil con prejuicios sociales y científicos". ${ }^{4}$ Para el caso de México, las investigaciones de Susie Porter han abierto camino en el estudio no sólo de las condiciones materiales del trabajo de las mujeres a finales del siglo xix y comienzos del xx. También han indagado los discursos públicos que reflejan políticas,

${ }^{4}$ Ulla WiKander, "Guerras mundiales, fascismo y racionalización. Estabilización de la división del trabajo según sexo (1914-1950)”, en De criada a empleada. Poder, sexo y división del trabajo (1789-1950), Madrid, Siglo Veintiuno Editores, 2016, p. 172. 
relaciones laborales y organización en relación con el trabajo de las mujeres. ${ }^{5}$

Desde el punto de vista de los estudios de género, estos trabajos han analizado los argumentos morales de estos discursos, así como los significados asociados a la defensa del honor, la honra y la honradez. ¿Qué es un trabajo honrado para un hombre o una mujer? ¿Cómo mantiene la honra un hombre a partir de su trabajo? Pensar en la honra que brinda el trabajo de los empleados es una vía para entender el significado social de tener o no tener una ocupación u oficio. Wikander recuerda que con el ascenso de la burguesía y mayores posibilidades financieras, las mujeres "fueron liberadas" de su trabajo "para dedicarse exclusivamente a la casa y a los hijos [...] Entre la burguesía se impuso la idea de que las mujeres eran 'económicamente dependientes' y los hombres asalariados 'económicamente independientes' y el 'sostén de las familias'”. ${ }^{6}$

Esos prejuicios construidos socialmente fueron la base para definir actuaciones de género en los diversos puestos de trabajo. Muchos oficios cambiaron de género o se atribuyeron a uno de ellos de acuerdo con los estereotipos construidos para hombres y mujeres. Por ejemplo, los escribanos de tradición colonial que se destacaban por su caligrafía fueron reemplazados, primero por hombres que dominaban la taquigrafía o la mecanografía, $\mathrm{y}$ a lo largo de la primera mitad del siglo xx, por mujeres que adquirieron los mismos conocimientos en escuelas comerciales. El oficio de secretaria fue asignado a las mujeres, generó estereotipos sobre valores y actitudes de quienes lo ejercían y, en muchos casos, se asignaron salarios bajos.

\footnotetext{
${ }^{5}$ Susie Porter, Mujeres y trabajo en la ciudad de México. Condiciones materiales y discursos públicos (1879-1931), México, El Colegio de Michoacán, 2008. ${ }^{6}$ Ulla WikAnder, "Guerras mundiales, fascismo y racionalización. Estabilización de la división del trabajo según sexo (1914-1950)", en De criada a empleada. Poder, sexo y división del trabajo (1789-1950), Madrid, Siglo Veintiuno Editores, 2016, pp. 34 y ss.
} 
El mundo del trabajo en las oficinas públicas y privadas ha sido materia de análisis en México y Argentina por investigadoras como Susie Porter y Graciela Queirolo.7 Para el caso de Europa, la misma Wikander ha establecido esta trayectoria de "criada a empleada" para caracterizar el tipo de trabajo asignado socialmente a las mujeres en cada momento de la historia. Otras variables han sido tomadas en cuenta por estas investigaciones en relación con la edad, el estado civil y el origen social. Esta reflexión sobre las condiciones de trabajo y el género también ha sido abordada desde el punto de vista de la construcción de masculinidades para reflexionar sobre las condiciones laborales. ${ }^{8}$

También se han estudiado el origen y la identidad social de empleados y trabajadores. Para el caso de quienes laboraban en la burocracia, ha sido muy común la asociación entre trabajo en la burocracia pública y privada y la pertenencia a la clase media. Éste ha sido tema de amplio debate a partir de los trabajos sobre la formación de estos sectores y las polémicas que ha habido en torno a la existencia de las mismas o a la invención en el siglo xix de una clase que simbolizara los valores de trabajo y civilización encarnados por el mundo moderno. ${ }^{9}$ Como

\footnotetext{
7 Susie Porter, "Empleadas públicas: normas de feminidad, espacios burocráticos e identidad de la clase media en México durante la década de 1930", en Signos Históricos, 6: 11 (2004), pp. 41-62; Graciela QueIrolo, "Saberes profesionales, movilidad ocupacional e inequidad laboral: el trabajo femenino en el sector administrativo (Buenos Aires, 1910-1950)", tesis de doctorado en historia, Buenos Aires, Universidad de Buenos Aires, 2014.

${ }^{8}$ Ejemplos de trabajos sobre trabajo y construcción de masculinidades son los artículos de Silvana PALERmo, "El derecho a mantener el hogar: las demandas obreras en la gran huelga ferroviaria desde una perspectiva de género: Argentina, 1917", en Andrea ANDÚJAR et al., Vivir con lo justo. Estudios de historia social del trabajo en perspectiva de género. Argentina, siglos XIX y XX, Rosario (Argentina), Prohistoria Editores, 2016, pp. 81-102.

9 Ezequiel Adamovsky, "Clase media: problemas de aplicabilidad historiográfica”, en Ezequiel Adamovsky, Sergio E. Visacovsky y Patricia Beatriz VARgAS, Clases medias. Nuevos enfoques desde la sociología, la historia y la antropología, Buenos Aires, Ariel, 2014, pp. 161 y ss.; Ricardo López Pedreros,
} 
se apunta en dos de los artículos del dossier, los empleados en México (y también ocurre en otros países de América Latina) eran considerados como miembros de la clase media a pesar de que sus condiciones no fueran las mismas de la pequeña burguesía europea decimonónica (capa compuesta por comerciantes y empresarios acomodados). Sin duda alguna, éste es un tema por explorar. Además de indagar las identidades de estos empleados, la autopercepción como clase media por los mismos contemporáneos nos lleva a pensar en su interés por distinguirse de otros sectores sociales. Este afán de distinción social se suma al respeto por las convenciones sociales y la propensión hacia el consumo y el cuidado de la apariencia física.

Los artículos de este dossier exploran tres perspectivas del empleo público: los empleados de las comisarías de policía, las trabajadoras sociales en la década de 1930 y una reflexión sobre la capacitación y las características de los empleados públicos del Distrito Federal al comenzar el siglo pasado.

El artículo de Diego Pulido explora el mundo del trabajo en las comisarías de la capital mexicana entre 1870 y 1920 . El texto busca no sólo estudiar las condiciones laborales, sino también sus interacciones sociales y las diferencias entre los diversos tipos de empleados en una comisaría de policía. Examina cómo vivían el día a día en sus lugares de trabajo y qué tanto cambiaron sus condiciones con los cambios políticos en la década revolucionaria. En la parte final, también reflexiona sobre los abusos de los funcionarios en contra de los habitantes de las diversas demarcaciones de la ciudad. El autor pretende "dar rostro social a las burocracias en el proceso de formación del

\footnotetext{
“'Ser clase media no es algo que se pasa de la noche a la mañana': empleados, mujeres de oficina y la construcción de las identidades de clase media en Bogotá, 1930-1950”, en Sergio VISACOvsky y Enrique GarguIN (eds.), Moralidades, economías e identidades de clase media. Estudios históricos y etnográficos, Buenos Aires, Editorial Antropofagia, 2009, pp. 161-194.
} 
Estado mexicano y, al mismo tiempo, abonar a la historia social de las policías modernas".

El texto de María Dolores Lorenzo aborda a las mujeres dedicadas al trabajo social en la Beneficencia Pública del Distrito Federal de 1930 a 1937, un momento de expansión de las acciones asistenciales del gobierno en relación con la inspección de los pobres de la capital mexicana. Para ello explora las metodologías de intervención e investigación que comenzaron a ser habituales en este trabajo por estos años y que pretendían darle un carácter científico al conocimiento sobre los pobres y mendigos. A la autora le interesa el reconocimiento del trabajo social como una actividad destinada a las mujeres. El tema principal del artículo no ha sido muy explorado por la historiografía y está escrito a partir de una cuidadosa revisión de fuentes primarias y del diálogo con historiografía relevante. Sin duda, el caso muestra la forma como se feminizaron ciertos oficios y como se fue profesionalizando esta actividad. Los perfiles presentados permiten establecer algunas de las características del trabajo social y señalar las desigualdades frente a los trabajos realizados por hombres. Además, el texto permite conocer cuál era el tipo de asistencia que se brindaba a los pobres y a los indigentes y cómo se sustentaba este tipo de auxilio.

Por su parte, el artículo de Mario Barbosa estudia la capacitación y el posicionamiento social de empleados y empleadas del Distrito Federal en las primeras décadas del siglo xx. El texto se propone analizar el peso de los programas de capacitación comercial y administrativa en las posibilidades laborales y en la percepción de los propios sectores que buscaban un empleo administrativo. También busca evaluar si la capacitación posibilitaba un mejoramiento en la posición social de estos pobladores. Dando continuidad a investigaciones anteriores, el autor explora el peso creciente de la capacitación en tareas técnicas y administrativas, tanto en la formación de personal especializado como en los perfiles de sectores educados que buscaban un ascenso 
social. Para ello, el autor explora los contenidos y la cobertura de los programas de formación administrativa, así como las percepciones públicas de la capacitación y de los sectores empleados en la burocracia capitalina. En la última parte del texto también aborda las autopercepciones como clases o sectores medios de estos empleados y empleadas y señala que es un tema para seguir explorando para entender a quiénes se llamaba y quiénes se identificaba como clases medias, en un momento en que las condiciones materiales no eran muy distintas entre estos sectores y los más pobres de la ciudad.

Con estos artículos esperamos continuar abriendo brechas en la historia del trabajo, en el estudio de las identidades sociales y en las discusiones sobre la necesaria caracterización del mundo de los llamados sectores medios, grupos sociales que buscaban diferenciarse por sus actitudes y por el tipo de trabajo que realizaban. Los textos quieren abonar a las discusiones historiográficas que hemos presentado en estas páginas y a una historia social que incorpore la investigación sobre otros sectores sociales y sobre otros tipos de trabajos que hasta ahora no han sido tema de una indagación más amplia.

Mario Barbosa Universidad Autónoma Metropolitana-Cuajimalpa 